Motrivivência Ano XXII, No 34, P. 122-135 Jun./2010

DOI:10.5007/2175-8042.2010n34p122

\title{
MULTIPLICAÇÃO E CONVERGÊNCIA DAS MÍDIAS: desafios para a educação física escolar
}

\author{
Rodrigo Cordeiro Camilo' \\ Mauro Betti ${ }^{2}$
}

\begin{abstract}
Resumo
Este artigo apresenta reflexões pedagógicas sobre as relações entre as mídias e Educação Física escolar, num cenário em que as tecnologias digitais facilitam e ampliam o acesso aos meios de informação e comunicação. Há então necessidade de aproximação da Educação Física às mídias, em face de sua importância nas representações simbólicas e no comportamento dos alunos no âmbito da cultura corporal de movimento. As intenções primárias das mídias não são necessariamente compatíveis com as finalidades escolares. Esta aparente contradição

Abstract

This article presents pedagogical reflections on the relationship between media and physical education, a scenario in which digital technologies facilitate and expand access to media. Then there is the need to approach physical education to the media, given its importance in symbolic representation and behavior of students within the movement body culture. The primary intentions of the media are not necessarily compatible with the purposes of school. This apparent contradiction leads us

1 Professor na rede estadual de ensino de São Paulo na disciplina Educação Física. Mestrando pelo Programa de Pós-Graduação em Educação da Faculdade de Ciências e Tecnologia - Unesp - Presidente Prudente. Contato: rodrigoccamilo@ig.com.br.

2 Professor-adjunto do Departamento de Educação Física da Faculdade de Ciências da Unesp - campus de Bauru e Docente do Programa de Pós-Graduação em Educação da FCT/Unesp campus de Presidente Prudente. Contato: mbetti@fc.unesp.br.
\end{abstract}


leva-nos a indagar, em diálogo com a área de mídia-educação, quais seriam as potencialidades das mídias como estratégia de ação pedagógica.

Palavras-chave: mídias; escola; Educação Física; mídia-educação.

\section{Introdução}

Diversas pesquisas educacionais demonstram uma grande preocupação com a investigação das relações que se configuram entre a sociedade e os meios de comunicação. Mcluhan (1964) foi um dos pioneiros a colocar em xeque uma ingênua visão de neutralidade dos meios tecnológicos.

É de extrema importância uma revisão histórica dessa relação homem-máquina e de como isso suscitou diversas mudanças na organização social, atingindo proporções globais. Contudo, a proposta neste texto é o destaque de reflexões a partir do cenário atual, no qual as tecnologias de informação e comunicação, que chamaremos aqui de mídias ${ }^{3}$, estão presentes no cotidiano e alcançam número cada vez maior de usuários, fenômeno to wonder, in dialogue with the area of media education, which would be the potential of media as a strategy for pedagogical action.

Keywords: media; school; physical education; media-education.

que foi facilitado e ampliado com o advento das tecnologias digitais.

Telefones celulares que registram imagens e conectam-se à internet, ipods, mp3, sites de relacionamento, jogos eletrônicos, google, blogs, youtube, são equipamentos, serviços, produtos e marcas cada vez mais presentes na vida de todos, em especial do mais jovens. Vivemos um momento de multiplicação e convergência das mídias (JENKIS, 2008). Tal cenário apresenta um dinamismo surpreendente, que Martín-Barbero (2006, p.64) entende como fruto de uma lógica mercadológica que estimula uma "comunicabilidade crescentemente subordinada a rentabilidade". As mudanças têm atingido até a mais popular das mídias - a televisão. Embora ainda seja predominante nas casas brasileiras, cede espaço cada vez maior às mídias que,

3 Entendemos por "mídias" os tradicionais meios de comunicação de massa, como jornais, rádio e televisão, assim como as novas tecnologias da informação e comunicação, as tecnologias e instrumentos usados para reunir, compartilhar, distribuir informação mediante o uso de redes de computadores e convergência de diversos equipamentos (computador pessoal, telefone celular etc.). A opção pelo uso do plural decorre do entendimento compartilhado com Santaella (1996), que vê uma crescente proliferação e diferenciação das mídias, cumprindo cada uma delas funções específicas e intercomplementares. 
apoiadas nas tecnologias digitais, possibilitam uma maior interação e autonomia dos receptores/consumidores na escolha, veiculação e até produção dos conteúdos. São representadas principalmente por videogames e pela internet, nos jogos online e diversos sites de relacionamento e troca de dados entre usuários. Tal fato se confirma principalmente em nosso país. Em pesquisa recente ${ }^{4}, \mathrm{o}$ Brasil apareceu como o único entre os países participantes da pesquisa em que a internet já superou a televisão como passatempo favorito. Já segundo Sant 'Agostino (2009) mostra, na industria do entretenimento, os segmentos de maior expansão são o dos videogames e o da internet, cujos percentuais crescem anualmente e movimentam bilhões de dólares.

A perspectiva que pretendemos explorar aqui é o reconhecimento de que a proliferação do acesso aos meios de informação e comunicação por (quase) todos os segmentos sociais, com as mais diferentes motivações, ao oferecer à população acesso a informações e bens culturais, os quais possivelmente não seriam apresentados acessados de outra maneira, "alimentam" os processos de significação e representação de realidade. Sobre esta perspectiva torna-se relevante a escola, instituição social de formação cultural dos indivíduos, debruçar-se avidamente na análise e compreensão deste fenômeno para melhor conduzir seu trabalho.

E a Educação Física escolar $^{5}$ ? Está isenta das influências midiáticas? Muito pelo contrário, e esta pergunta já foi respondida por inúmeros pesquisadores, com destaque para Betti (1998, p.80) que inicia seu texto com a seguinte frase: "A mídia está em toda parte e o esporte está em toda mídia".

Concebendo a Educação Física escolar como uma disciplina que trabalha criticamente com a Cultura Corporal de Movimento ${ }^{6}$, faremos mais adiante algumas considerações de como se dão as relações entre mídias, alunos e Educação Física escolar. Apontaremos também possibilidades metodológicas para

4 Pesquisa intitulada "O Futuro da Mídia", da Deloitte/ Harrison Group, disponível em: http://info abril.com.br/noticias/internet/brasileiro-prefere-web-a-tv-diz-pesquisa-18052009-24.shl

5 Cultura Corporal de Movimento é considerada "aquela parcela da cultura geral que abrange as formas culturais que se vêm historicamente construindo, nos planos material e simbólico, mediante o exercício da motricidade humana - jogo, esporte, ginásticas e práticas de aptidão física, atividades rítmicas/expressivas e dança, lutas/artes marciais, práticas alternativas" (BETTI, 2006, p.53).

6 Cultura Corporal de Movimento é considerada "aquela parcela da cultura geral que abrange as formas culturais que se vêm historicamente construindo, nos planos material e simbólico, mediante o exercício da motricidade humana - jogo, esporte, ginásticas e práticas de aptidão física, atividades rítmicas/expressivas e dança, lutas/artes marciais, práticas alternativas" (BETTI, 2006, p.53). 
o encaminhamento de propostas de atualização pedagógica de suas atividades, a fim de contemplar essas relações.

\section{A presença das mídias na Edu- cação Física escolar}

É importante destacar que, quando falamos sobre a presença das mídias no cotidiano das pessoas, não podemos reduzir a análise do fenômeno apenas à instrumentalização do cidadão, que cada vez mais pode usufruir de uma diversidade de aparelhos eletrônicos com um baixo custo, que podem ser carregados no bolso sem desconforto, que mobíliam sua casa e local de trabalho com finalidades variadas: desde facilitar as atividades diárias até a oferta de possibilidades de lazer. Martín-Barbero (2006, p. 54) alerta que, mais do que a introdução de uma quantidade inusitada de novas máquinas, há a introdução de um "novo modo de relação entre os processos simbólicos - que constituem o cultural - e as formas de produção de distribuição dos bens e serviços".

Diversas teorias que tratam de conceituar as mudanças nas formas de organização social com o advento das mídias foram analisadas com muita propriedade por Eco
(2006), no clássico livro "Apocalípticos e Integrados", publicado originalmente em 1964. A partir da leitura de distintos posicionamentos à respeito da cultura de massa ${ }^{7}$, cuja origem é proclamada no momento em que as classes populares obtém acesso e compartilham dos meios de comunicação e das informações veiculadas, reconhece posturas céticas ou otimistas sobre as quais demonstrou a existência de um conflito teórico entre apocalípticos e integrados, apesar do próprio autor considerar superficial rotular de forma dicotômica essas opiniões sobre a cultura. Para Eco (2006), os apocalípticos seriam aqueles que concebem a cultura de massa como radicalmente má, uma anticultura, alienante e deturpadora daqueles elementos realmente reconhecidos como cultura: os eruditos; consideram-na também condicionada por uma lógica industrial, que vulgariza a verdadeira cultura. Entre os integrados configuram-se aqueles que apóiam todo processo de proliferação das mídias e seus conteúdos, como uma "homeostase do livre mercado" (ECO, 2006, p.49). Concebem o fenômeno como bom em si, num discurso de democratização dos bens culturais.

7 È importante colocar que o pesquisador faz críticas ao uso desse termo, entendendo-o como um "conceito fetiche", com pouca clareza conceitual e pouca utilidade nas questões que considera que realmente deveriam ser discutidas. 
Os integrados raramente teorizam e assim, mais facilmente utilizam-se cotidianamente desses meios em todos os níveis.

Parece-nos que as reflexões de Umberto Eco são ainda importantes, mesmo com o surgimento de novos meios que superaram em termos de possibilidades os tradicionais meios de comunicação de massa.

Um avanço original de Eco (2006) em seus apontamentos sobre o tema está nas propostas de superação desta dicotomia, que retrata apenas parcialmente a realidade. Começa por tecer críticas àqueles que avaliam as mudanças seguindo medidas e modelos de interpretação obsoletos, que já não fazem mais parte do contexto atual. O que o autor propõe é o reconhecimento da presença inevitável dos meios de comunicação no cotidiano e nas representações da sociedade e, partindo desta premissa, considera que é preciso buscar reflexões sobre como relacionar-se de forma ética com esses meios. Segundo Eco (2006, p.50):

A falha está em formular o problema nestes termos: "é bom ou mal que exista a cultura de massa?" (mesmo porque a pergunta subtende a desconfiança reacionária na ascensão das massas, e pretende pôr em dúvida a vali- dade do progresso tecnológico, do sufrágio universal, da educação estendida às classes subalternas etc.).

Quando, na verdade, o problema é: "do momento em que a presente situação de uma sociedade industrial torna ineliminável aquele tipo de relação comunicativa conhecido como conjunto dos meios de massa, qual a ação cultural possível a fim de permitir que esses meios de massa possam veicular valores culturais?"

Até agora, "preparamos o terreno" para justificar nossas reflexões e entendimentos sobre as características próprias das mídias e das relações que se estabelecem com os sujeitos receptores, em diferentes aspectos. Considerando como característica relevante do mundo globalizado a presença maciça dos meios de comunicação na vida social e subjetiva, Santaella (1996, p. 29) compreende que os processos comunicativos que envolvem esses meios também são processos culturais, que criam seus códigos específicos e signos, consequentemente produzindo "efeitos de percepção, processos de recepção e comportamentos sociais que lhes são próprios", admitindo a presença de uma "Cultura das Mídias". 
Babin e Kouloumdjian (1989) também partilham da idéia do surgimento de uma cultura audiovisual, partindo da observação de comportamentos e linguagens utilizadas pelas novas gerações. O poder de apreensão que esta cultura possui sobre a atenção de seus receptores tem como características principais uma intensa carga afetiva (que atinge o subconsciente do receptor), pouca exigência de abstração e informações perceptíveis a partir de múltiplos sentidos. Estas qualidades atribuídas à cultura audiovisual são fruto de interações e complementaridades entre som, palavra e imagem, processo denominado pelos autores como mixagem, cuja assimetria, não linearidade e velocidade das imagens constitui uma espécie de "mosaico", que prende a atenção dos diversos receptores.

Belloni (2001) discorre sobre a capacidade das mídias gerarem situações de mania e/ou dependência, principalmente sobre crianças e adolescentes (receptores em potencial dessas tecnologias), partindo da idéia de que promovem uma realidade virtual, que pode fazer com que estes indivíduos se distanciem gradativamente da realidade concreta.

A cultura corporal de movimento, com especial atenção ao esporte (conteúdo também bastante presente na Educação Física escolar) é objeto de grande veiculação midiática. Tal fato pode ser observado em revistas, jornais, programas televisivos, internet, videogame, entre outros. As pessoas conversam sobre o que assistem na TV (sobre os diferentes programas) ou leram nos jornais. Trocam idéias e discutem opiniões baseadas nas informações veiculadas por esses meios. Emocionam-se, ficam indignadas, divertemse e entretêm-se com os programas e matérias televisivos de diversos gêneros. A presença das mídias (o que inclui os conteúdos veiculados) exerce relevante influência nos processos de significação da sociedade como um todo. Poderíamos dizer que elas também constroem a cultura corporal de movimento. É nesse sentido, por exemplo, que Weis (1986) afirma que "a mídia gera uma nova hierarquia de valores" (apud BETTI, 1998, p.34).

Movidas por interesses em primeira instância econômicos, as mídias promovem com o fenômeno esportivo um processo de "espetacularização" (BETTI, 1998) por meio do sensacionalismo, seleção de imagens e interpretações. Propõem ao receptor padrões e modelos sobre o esporte e outras formas da cultura corporal de movimento. Isso cria novas formas de percepção e significação de uma prática corporal além do "vivenciar corporalmente". Por isso Betti (1998) acredita não 
ser mais possível dissociar o esporte contemporâneo dos meios de comunicação de massa.

Essas tecnologias são mais do que ferramentas a serviço do homem, e uma vez que transmitem conteúdos mais atraentes aos alunos que a escola convencional, são mais significativas sobre os modos de "perceber o mundo, de se expressar sobre ele e de transformá-lo" (BELLONI, 2001, p.17). Dessa forma, a utilização dessas tecnologias pelo homem precede sua própria transformação.

Frequentemente, os alunos aparecem nas escolas envolvidos com novas práticas corporais. Tal afirmação pode ser estendida a diversas outras coisas: diferentes modos de se vestir; novas gírias; frases de efeito; músicas. Todo professor já se deparou com esta situação. No caso das práticas corporais, temos recentemente o exemplo do Le Parkour ou do Rebolation. Embora estas práticas sejam re-significadas pelos alunos de acordo com seus valores e representações, tem referência, na maioria das vezes, nos conteúdos veiculados nas mídias. Curiosamente, pode-se dizer que essas práticas, tão presentes nas culturas juvenis de variados grupos, têm ocupado o interesse desses jovens, substituindo o lugar dos tradicionais conteúdos da Educação Física escolar, em especial o esporte. A resistência a esses tradi- cionais conteúdos é considerada um problema por muitos professores, o que, em nosso entendimento, evidencia a dificuldade que tem tido a Educação Física em realizar uma atualização pedagógica que reconheça as manifestações emergentes na cultura corporal de movimento, assim como as fontes de referências que fornecem seus significados para os alunos.

Para isso, é muito importante o professor prestar atenção no que acontece durante as aulas e fazer relações com o contexto de vida dos alunos. Vivemos numa época em que muitas coisas acontecem ao mesmo tempo, com relativa efemeridade. Pois, como entende Renaud (apud MARTÍN-BARBERO, 2006, p.76):

A linha da cultura se rompeu, e também com ela, a ordem temporal sucessiva. A simultaneidade e a mesclagem ganharam o jogo: os canais se intercambiam, as manifestações cultas, as populares e as de massas dialogam e não o fazem em regime de sucessão, mas, sim, sob a forma de um cruzamento que acaba por torná-las confusas.

Apresentamos a seguir, para provocar uma reflexão inicial, algumas situações testemunhadas por um dos autores deste texto, na 
condição de professor de Educação Física em uma escola pública:

Situação 1: um aluno não participa das aulas de educação física alegando preguiça ou indisposição, no entanto, é um assíduo praticante de "step dance" com o grupo de amigos no Shopping Center; ou passa a tarde toda depois da aula praticando movimentos de Street Dance, em casa ou em algum espaço público com os colegas.

Situação 2: Na televisão, um grupo de "happy rock" que se apresentava pela primeira vez na TV, mas já era febre entre adolescentes, conquistando seu público através da divulgação de suas músicas por vídeos na internet e sites de relacionamento. Logo nos dias seguintes, alguns alunos foram para as aulas de Educação Física trajando roupas coloridas e diversos acessórios: óculos (sem lentes), boné, pulseiras e cintos metálicos.

Situação 3: Uma aluna chorava e não queria participar da aula por que sua colega de classe não a adicionou como amiga num site de relacionamento, mas adicionou outras meninas da classe.

Situação 4: Houve briga durante um jogo de futsal entre os alunos, pois enquanto alguns reclamavam que o jogador do time adversário estava simulando todas as faltas, outros zombavam dos colegas imitando "dancinhas" dos jo- gadores profissionais que assistiam na TV quando faziam gol.

Os quatro casos de uma forma ou de outra têm a presença das mídias envolvida. Não merecem uma reflexão mais aguda? $\mathrm{O}$ que pode fazer um professor diante destes acontecimentos em suas aulas?

\section{Midia-Educação: alternativas para o currículo escolar}

Sob várias denominações, em vários países do mundo, um movimento de caráter científico e pedagógico (no sentido amplo do termo) tem se preocupado com as mídias e suas implicações sociais, investindo particularmente nos processos de recepção das mensagens pelos sujeitos. No Brasil, a denominação mais usual é "mídiaeducação". Segundo Fantin (2006), esse campo de estudos constituiu-se com base em dois outros campos que se invadem mutuamente numa forte relação: o da educação e o da comunicação. Embora reconheça que esses campos apresentem lógicas diferenciadas, "é no contexto da discussão sobre esta interface educação-comunicação que aparece a mídia-educação" (p.29). Masterman (apud FANTIN, 2006, p. 71-72) destaca os seguintes princípios para esclarecer a amplitude desse objeto: 
o conceito central e unificante da mídia-educação é o de representação; um dos objetivos fundamentais da mídia-educação é o de desmascarar a falsa naturalização das mídias revelando seu caráter de construção; a mídiaeducação é principalmente investigativa, não procura impor valores culturais específicos; a mídia-educação se constrói em torno de alguns conceitos-chaves como instrumentos de análise e não como conteúdo alternativo; a mídia-educação é um processo de longo prazo e dura toda vida; a mídia-educação visa não só a compreensão crítica mas também a autonomia crítica; a eficácia da mídia-educação pode ser avaliada a partir de dois critérios gerais: a capacidade do aluno aplicar aquilo que conheceu em situações novas e o grau de desempenho, interesse e motivação demonstrado; a mídia-educação parte sempre da atualidade (embora não se limite a ela).

Portanto, toda discussão a qual se propõe a mídia-educação almeja a superação de propostas de educação para as mídias que se reduzam apenas a leituras críticas dos meios, ou mesmo a negação destas com a adoção do postulado de que as mídias não podem trazer benefício algum ao processo educativo. Belloni (2001) faz considerações sobre a mídia-educação traçando caminhos nessa mesma direção. Argumenta que o trabalho escolar nesse âmbito deve favorecer a renovação dos papéis do professor e do aluno: estimulando o professor coletivo, que trabalha em equipe e assume uma postura de professor-mediador; e o aluno autônomo, que desenvolve uma auto-aprendizagem no seu envolvimento com as mídias ${ }^{8}$. Belloni (2001) e Fantin (2006) concordam que a integração das mídias no sistema educacional deva superar tanto a visão instrumental como a visão conteudista no trabalho pedagógico, construindo práticas sobre duas dimensões indissociáveis: como ferramenta pedagógica, e como objeto de estudo, que é complexo e multifacetado.

Ponto importante no diagnóstico levado a cabo pelo campo da mídia-educação é o fato de que a instituição escolar está em franca defasagem com relação às demandas sociais e as culturas das gerações mais jovens:

8 É importante destacar que a pesquisadora utiliza o termo "TIC" (tecnologias de informação e comunicação) ao invés de "mídias". Optamos, com o intuito de manter uma coerência textual e facilitar o entendimento do leitor, por utilizar este último termo, considerando que este se relaciona ao mesmo objeto de estudo da pesquisadora. 
As TIC avançaram mais rapidamente do que a própria informação. Neste sentido, é justo dizer que estas tecnologias trouxeram problemas que transcendem o nível meramente técnico para se situar na esfera social e cultural: são os problemas das necessidades novas, dos conteúdos a ser criados e dos novos usos que estão sendo inventados e tendem a se desenvolver progressivamente, segundo uma dinâmica própria bem diferente da lógica da oferta técnica (MERCIER apud BELLONI, 2001, p. 21).

É com esses argumentos que precisamos abandonar a concepção de que as mídias determinam o sujeito para partimos para reflexões sobre o que esses sujeitos fazem com essas mídias. Outros pesquisadores também compartiIham da idéia de que escola deve atualizar sua tarefa pedagógica, na direção de educar os alunos para que estes compreendam e relacionem-se criticamente com a cultura audiovisual (MORÁN, 1995; FERRÉS, 1996; OROZCO-GÓMEZ, 1997; BETTI, 1998).

Morán (1995) incentiva o uso do vídeo e caracteriza diferentes formas de sua utilização como recurso pedagógico, principalmente pela sua forma multilinguística. $\mathrm{O}$ conceito de multilinguístico pode ser explicado por meio do que MartínBarbero (2006) entende por hipertexto, que consiste num trabalho interativo envolvendo sons, imagens e textos escritos. Faz críticas ao uso deste material com uma finalidade em si mesmo, aconselhando que o professor busque dos alunos percepções também racionais, além de emocionais e intuitivas.

Orozco-Gómez (1997, p.57) avalia a TV como uma "escola paralela", que penetra nos lares "sem licença para ensinar", exercendo forte concorrência, muitas vezes desleal, com as outras instituições encarregadas na educação das crianças, como a escola e a família. Entende que os professores devem reconhecer o papel significativo que os meios de comunicação de massa exercem no aprendizado das crianças. A partir dessa constatação, consideramos que os docentes não podem adotar posturas de rivalidade ou concorrência com esses meios, muito menos autoritárias, no sentido de querer controlar, coibir, ou negligenciar as diferentes manifestações envolvendo os alunos e suas relações com as mídias no cotidiano escolar.

Proposta semelhante às apresentadas anteriormente (BELLONI, 2001; FANTIN, 2006) é a de Ferrés (1996, p.93), que sugere duas dimensões necessárias para uma integração adequada da televisão 
à sala de aula, mas que podemos ampliar para todas as mídias: "educar no meio e educar para o meio". Educar com o meio pressupõe a sua utilização como instrumento de otimização do ensino-aprendizagem. Educar no meio significa, resumidamente, transformá-lo em objeto de estudo, ensinando seus mecanismos de funcionamento e orientando a análise crítica dos seus conteúdos. Essas dimensões são complementares, e ambas devem ser alcançadas pelo trabalho pedagógico.

Para atender tal perspectiva, a formação dos professores deve favorecer o desenvolvimento das competências didático-pedagógicas necessárias. Babin e Kouloumdjian (1989) ressaltam a importância dos professores compreenderem a linguagem audiovisual, o que se consegue com momentos de imersão na e exposição a esta linguagem, assim como momentos de distanciamento, para chegar a uma reflexão crítica que possibilite a apropriação e possibilidades de reconstrução.

Há necessidade de aproximação da escola às mídias, inclusive pela Educação Física, em face da sua presença na construção simbólica e no comportamento dos alunos. As intenções primárias das mídias não são necessariamente compatíveis com os objetivos educacionaisescolares. Esta aparente contradição leva-nos a indagar quais seriam as potencialidades das mídias e suas possibilidades como estratégia de ação pedagógica.

\section{Considerações Finais}

A Educação Física, na qualidade de disciplina escolar, pode engajar-se nesse processo de incorporação das mídias no currículo escolar. Qual contribuição pode oferecer para que a escola atualize suas tarefas pedagógicas tradicionais (sem delas abrir mão), adequando-as a novas necessidades sociais, aproximando-se das culturas infanto-juvenis e da nova geração de alunos já formados sob a égide da "cultura das mídias"?

Ousamos dizer que não há respostas prévias e nem manuais que respondam estas questões (nem deveria haver!). Não podemos de forma alguma negar todo o conhecimento acumulado nas pesquisas educacionais, sem os quais não poderia estar aqui fazendo estas reflexões. No entanto, ao considerar o nosso objeto de estudo um fenômeno dinâmico, histórico e cultural, condenado à impossibilidade de controle absoluto e previsões exatas, precisamos reconhecer que os diferentes problemas que aparecem durante o processo educativo eventualmente pedem diferentes modos de investigação, diferentes olhares, pedem criatividade e ousadia. Reiterando, não 
devemos negar teorias prévias, mas estas devem estar sempre subordinadas ao contexto observado e não o contrário (FOUREZ, 1995).

Devemos conceber a educação como um objeto de estudo aberto (SACRISTÁN, 1983), sempre inconcluso. Do contrário, tendo a presunção do reconhecimento desse objeto como algo pré-existente, já delimitado, tomaremos a educação apenas como reprodutora de estágios culturais já atingidos.

Sobre o caminho desta constante busca do objeto mesmo da educação, Sacristán (1983, p.32) comenta:

[...] iremos captando sua essência à medida que o vamos perseguindo com a prática educativa, interpretando-o ao mesmo tempo que vai se condensando no decurso de uma experiência. Essa peculiaridade dá às ciências da educação uma caracterização particular: a de serem radicalmente inconclusas.

Por isso, temos que admitir que as produções no campo da "mídia-educação física" que se pautaram por investigar os meios de comunicação de massa, em especial à $T V$, talvez não respondam mais às necessidades atuais, já que o atual cenário comunicacional, como já vimos, caracteriza-se pela multiplicação e convergência das mídias, fenômeno acelerado com o advento das tecnologias digitais.

Outro avanço importante ainda por realizar mais cabalmente é a necessidade de investigar a prática pedagógica da Educação Física Escolar em situações reais de ensino, como clama Betti (2009). Tal aplicase também ao estudo das mídias no âmbito do ensino da Educação Física. Nessa direção, uma conclusão inicial, porém significativa, é que é preciso superar o uso meramente instrumental das mídias nas aulas, ou seja, focado apenas nos aspectos didáticos, de como operacionalizar os objetivos de ensino propostos, em detrimento de uma abordagem mais reflexiva e crítica sobre as próprias mídias (BETTI; MENDES; BETTI, PIRES, 2009).

O saber meramente instrumental é insuficiente quando se concebe um problema como sendo ontologicamente diferente de um problema técnico. Não queremos desconsiderar a relevância do saber técnico, entretanto, ele deve ocupar um papel diferente nesse novo cenário pedagógico.

$\mathrm{O}$ que pretendemos destacar com estas considerações é a complexidade e o dinamismo das práticas educativas, e a necessidade de buscar respostas em contextos reais de ensino e aprendizagem.

Apontamos aqui algumas reflexões que acreditamos ser bastante 
relevantes a respeito das possibilidades da linguagem audiovisual midiática no âmbito das práticas educativas da Educação Física. Não é um trabalho simples, e, ao contrário da velocidade com que aparecem novas situações problemáticas, o processo de reflexão sobre os valores éticos, políticos e ideológicos que estão envolvidos é bem mais lento. Mas é o espaço escolar o lugar desse "repensar". No caso aqui em evidência, reconhecer o aluno como produtor de conhecimento e re-significador do mundo a sua volta, trazer para o currículo escolar a discussão a cerca dessa pluralidade de informações que nos rodeiam, modelam condutas e opiniões. Não devemos negar a priori as novas mídias que aparecem constantemente nas mãos e bolsos dos alunos e em seus comportamentos. É tarefa da escola e, nesse caso, da Educação Física escolar, dar respaldo ao aluno em suas escolhas sobre como se relacionar com essas mídias e, portanto, elas precisam ser reconhecidas como meios e conteúdos de extrema relevância no currículo escolar.

\section{Referências}

BELLONI, M. L. O que é MídiaEducação. Campinas, SP: Autores Associados, 2001.
BABIN, P.; KOULOUMDJIAN, $M$. F. Os novos modos de compreender: a geração do audiovisual e do computador. São Paulo: Paulinas, 1989.

BETTI, M. A janela de vidro: esporte, televisão e educação física. Campinas: Papirus, 1998a. Midia e Educação: Análise da Relação dos Meios de Comunicação de Massa com a Educação Física e os Esportes. In: Seminário Brasileiro em pedagogia do esporte, Santa Maria, 1998. Anais: UFSM, Santa Maria, 1998b.

"Imagens e ação": uma pesquisa-ação sobre o uso de matérias televisivas em programas de educação física do ensino fundamental e médio. In: Movimento, Porto Alegre, v.12, n.02, maio/agosto, 2006, p.95-120.

Educação Física Escolar: ensino e pesquisa-ação. Ijuí: Unijuí, 2009.

BETTI, M.; MENDES, D. S.; PIRES, G. L. Imagem e ação: as mídias e a educação física escolar. In: BETTI, M. Educação Física Escolar: ensino e pesquisa-ação. Ijuí: Unijuí, 2009, p. 269 a 318.

COELHO, T. O que é Indústria Cultural. 6. ed. São Paulo: Brasiliense, 1983. 
ECO, U. Apocalípticos e Integrados. Tradução de Pérola de Carvalho. 6. ed. São Paulo: Perspectiva,2006. (Debates; 19).

FANTIN, M. Mídia-Educação: conceitos, experiências, diálogo Brasil-Itália. Florianópolis: Cidade Futura, 2006.

FERRÉS, J. Televisão e Educação. Porto Alegre: Artes Médicas, 1996.

FOUREZ, G. O método científico: adoção e rejeição de modelos. In: A construção das ciências: introdução à filosofia e a ética das ciências. São Paulo: Unesp, 1995.

JENKIS, H. Cultura da convergência. São Paulo: Aleph, 2008.

MCLUHAN, M. Os meios de comunicação como extensões do homem. Tradução: Décio Pignatari. São Paulo: Cultrix, 1964.

MARTÍN-BARBERO, J. Tecnicidades, identidades, alteridades: mudanças e opacidades da comunicação no novo século. In: MORAES, D. (org.). Sociedade Midiatizada. Rio de Janeiro: Mauad, 2006.
MORAN, J.M. O vídeo na sala de aula. In: Comunicação e Educação. São Paulo, n.2, jan/ abr.1995, p.27-35.

OROZCO-GOMÉZ, G. Professores e Meios de Comunicação: desafios e estereótipos. In: Comunicação e Educação. São Paulo, vol.3, n.10, set/dez.1997, p.57-68.

SACRISTÁN, J. G. Explicação, Norma e Utopia nas Ciências da Educação. Cadernos de Pesquisa, São Paulo, n.44; p.3134, fev. 1983.

SANT'AGOSTINO, L. H. F. Entretenimento na cibercultura: games e "experiências do pensamento". In: CARAMELLA, E. et al. (Org.). Mídias: multiplicação e convergências. São Paulo: Senac, 2009, p. 615627.

SANTAELLA, L. A cultura das mídias. São Paulo: Experimento, 1996.

Recebido: agosto/2010. Aprovado: outubro/2010. 